\title{
Prevalence and genetic correlation evaluation of dental fluorosis in rural population of Nagpur, India
}

\author{
Chetana S.Makade $^{1^{*}}$, Pratima Shenoi ${ }^{2}$, Mohit Gunwal ${ }^{3}$, Rajesh Kubde ${ }^{4}$, Varsha Uttarwar ${ }^{5}$, Manjusha Pradhan ${ }^{6}$, \\ Vidya Mokhade ${ }^{7}$
}

${ }^{1}$ Associate Professor, ${ }^{2}$ Professor and HOD, ${ }^{3}$ Assistant Professor, ${ }^{4}$ Professor, ${ }^{5-7}$ Lecturer, Dept. of Conservative Dentistry and Endodontics, VSPM DCRC, Nagpur, Maharashtra, India

*Corresponding Author: Chetana S.Makade

Email: makade.chetana@gmail.com

\begin{abstract}
Dental fluorosis (DF) is a tooth malformation related to ingestion of high amount of fluoride (F) during tooth development. According to various surveys $(1994,2000 \& 2002)$, it is clearly established that DF has increased incidences rates in the areas with fluoridated water ranging from $7.7 \%$ upto $80.9 \%$ and only $2.9 \%$ to $42 \%$ in areas without fluoridated water. It was being observed that $10-20 \%$ of the rural population reported to department with dental fluorosis belonged to non-fluoridated areas. Several studies suggested that there was a weak corelationship between drinking water \& DF severity.

Aim: The present study was undertaken to investigate prevalence of dental fluorosis and hereditary patterns of dental fluorosis in identified individuals among rural population in vicinity of Nagpur district.

Materials and Methods: A case control study was conducted at six rural places around Nagpur. The fluoride content was estimated from sample of drinking water from well and tap.384 individuals were selected using systematic random sampling method. A detailed case history was taken followed by reporting of DMFT and DMFS indices. The collected data was analyzed statistically using students't test.

Results: All the water samples tested reported F concentration varying with 0.267 to $1.081 \mathrm{mg} / \mathrm{ml}$. Prevalence of DF for individuals consuming well water(62.1\%) was found to be significantly higher(p<0.05) compared to tap water $(4.7 \%)$. The individuals with history of DF $(50 \%)$ had significantly higher prevalence $(\mathrm{p}<0.05)$ of fluorosis as compared to negative family history $(15 \%)$.

Conclusion: There was no correlation with DF and F concentration in drinking water, however its strong correlation exists with genetic component.
\end{abstract}

Keywords: Dental fluorosis (DF),

\section{Introduction}

Dental fluorosis (DF) is a tooth malformation produced by chronic ingestion of fluoride $(\mathrm{F})$ during tooth development that primarily affects enamel but can also affect dentin. However, dental fluorosis is a reflection of fluoride exposure only during the time of enamel formation., Fluorosis is a result of destruction of metabolic calcium \& phosphorus, leading to inhibition of active enzymatic process in human body, which interrupts the function of endocrine system leading to fluorosis. ${ }^{2}$ Major Psychological impact on persons self-esteemNational Institute of Mental health. ${ }^{3,4}$ Several animal and epidemiological studies have demonstrated that genetics plays a key role DF severity. ${ }^{5-8}$

Current status in India: Most severe problem associated with high $\mathrm{F}$ water occurs in China, India, Sri Lanka \& Africa. Maximum permissible limit 1.5 to $1.0 \mathrm{ppm}$ for India.(WHO 1998). In Vidarbha region of Maharahtra, Nagpur, Chandrapur, Gondia, Amravati \& Gadchiroli reported $\mathrm{F}$ concentration of $1.51-4.01 \mathrm{mg} / \mathrm{L}$ in ground water. DF has increased in areas with fluoridated water by 7.7$80.9 \%$ and $2.9-42 \%$ in non fluoridated water areas $10-20 \%$ of the rural population reported to our department with DF belonged to non-fluoridated areas. Several studies suggested that there was a weak co-relationship between drinking water \& DF severity. ${ }^{9,10}$

The present study was undertaken to investigate prevalence of dental fluorosis and hereditary patterns of dental fluorosis in identified individuals among rural population in vicinity of Nagpur district. The objectives of the study was to estimate the $\mathrm{F}$ level in drinking water sources(tap \& well),to study the distribution of DF by source of water(tap \& well) and to study the hereditary patterns of DF in identified individuals, if any.

\section{Materials and Methods}

A survey was conducted at six rural places around Nagpur. Sample of drinking water from well and tap was collected for estimation of fluoride content. Patients were screened and 384 individuals were selected using systematic random sampling method. A detailed case history was taken followed by examination. DMFT and DMFS indices were recorded. The collected data was analysed statistically using students t test.

Water samples from tap and well water were collected for estimation of $\mathrm{pH}$ and fluoride concentration using ion exchange method at (NEERI), Nagpur. The data collected was statistically analyzed using Chi square test.

\section{Results}

All the water samples tested reported $\mathrm{F}$ concentration varying with 0.267 to $1.081 \mathrm{mg} / \mathrm{ml}$. Prevalence of DF for individuals consuming well water(62.1\%) was found to be significantly higher $(\mathrm{p}<0.05)$ compared to tap water(4.7\%).The individuals with history of DF (50\%) had significantly higher prevalence $(\mathrm{p}<0.05)$ of fluorosis as compared to negative family history $(15 \%)$. [Table $1,2,3]$ 
Table 1: Estimation of Fluoride Concentration and $\mathrm{pH}$ of Water

\begin{tabular}{|c|c|c|c|c|c|}
\hline \multirow{2}{*}{\multicolumn{2}{|c|}{ Place }} & \multicolumn{2}{|c|}{ Fluoride concentration $(\mathrm{mg} / \mathrm{l})$} & \multicolumn{2}{|l|}{ pH } \\
\hline & & Tap water & Well water & Tap water & Well water \\
\hline Sillewada & & 1.06 & 0.287 & 8.338 & 6.828 \\
\hline Gondkhairi & & 1.631 & 0.808 & 7.653 & 7.359 \\
\hline Khapa & & 1.578 & 0.548 & 7.972 & 7.892 \\
\hline Badegaon & & 0.572 & 0.267 & 8.549 & 7.75 \\
\hline Kelwad & & 1.081 & 0.643 & 7.905 & 6.964 \\
\hline Waki & 0.847 & 0.831 & 7.674 & 7.279 & \\
\hline
\end{tabular}

Table 2: Oral Hygiene Habits and Fluorosis

\begin{tabular}{|c|c|c|c|c|}
\hline \multirow{2}{*}{$\begin{array}{l}\text { Oral hygiene } \\
\text { practice }\end{array}$} & \multicolumn{2}{|c|}{ Fluorosis } & \multirow[t]{2}{*}{ Total } & \multirow{2}{*}{$\begin{array}{c}\mathbf{P} \\
\text { value }\end{array}$} \\
\hline & Absent & Present & & \\
\hline No habits & 236 & 37 & 273 & \multirow{6}{*}{0.006} \\
\hline Kharra & 23 & 13 & 36 & \\
\hline Paan & 3 & 0 & 3 & \\
\hline Gutkha & 24 & 8 & 32 & \\
\hline Other & 33 & 5 & 38 & \\
\hline Total & $319(83.5 \%)$ & $63(16.5 \%)$ & $382(100 \%)$ & \\
\hline
\end{tabular}

Table 3: DMFT, DMFS index and Fluorosis

\begin{tabular}{|c|c|c|c|c|c|}
\hline Index & Fluorosis & N & Mean & SD & p value \\
\hline \multirow{2}{*}{ DMFT } & Absent & 319 & 1.8871 & 1.99838 & 0.76 \\
\cline { 2 - 5 } & Present & 63 & 1.8095 & 1.41258 & \\
\hline \multirow{2}{*}{ DMFS } & Absent & 319 & 3.6426 & 6.35116 & 0.84 \\
\cline { 2 - 5 } & Present & 63 & 3.0635 & 3.67587 & \\
\hline
\end{tabular}

\section{Discussion}

Vary widely between different geographic locations having almost same $\mathrm{F}$ concentration in drinking water.Increases with fluoride concentration in drinking water \& duration of exposure. ${ }^{11,12}$ Dissolved salts in drinking water, nutrition and habits also affect DF.Certain ethnic groups are more susceptible to DF. ${ }^{13}$

In normal situations during presecretary tomes process secretes a secretary vesicle containing amelogenin. At neutral $\mathrm{pH}$ these amelogenins form nanospheres that adhere to the growing crystals and foster its growt length and this generates protons. Amelogenins bind and neutralize protons.Whereas with fluorotic conditions there is disruption of secretary amelogenesis.F primarily accelerates crystal growth in thickness shown by hypermineralized line. This enhances proton production which cannot be buffered by available amelogenins. Thus the nanosphere disaggregates and detach from the crystal surface. This newly secreted matrix will not foster crystal growth till neutral $\mathrm{pH}$ is restored which is represented by hypomineralized line. In genetic study by Lee et al has demonstrated that $F$ includes elevation of F-actin in ameloblasts, which alters the cytoskeleton interfering Rho signaling pathway. Fincham et al 1995).Excessive F ingestion replaces the apatite structure thereby converting it to fluorapatite making the tooth discolored and brittle.

The present study deals with the prevalence of DF in non fluoridated five rural places of Nagpur district. The water samples revealed $\mathrm{F}$ concentration \& $\mathrm{pH}$ of water within normal limits. Overall 382 participants from 1,910 rural residents ranging from 12 to 40 years were screened.

The overall prevalence of DF was $16.5 \%$. The prevalence of fluorosis amongst individuals with positive family history $(75 \%)$ was significantly higher $(p<0.05)$.The results of our study were analogous to the findings of Clark DC(1994) who studied trends in prevalence of DF in North America. Pendrys DG(2000) found 65\% cases with mild to moderate enamel fluorosis in non fluoridated populations due to fluoride supplementation. Whereas remaining $34 \%$ has brushed during first two years of life using $\mathrm{F}$ dentrifices and more recommended quantity of paste. In addition Pendrys DG(2000) also found $65 \%$ cases with mild to moderate enamel fluorosis in non fluoridated populations due to fluoride supplementation under pre-1994 protocol. Whereas remaining $34 \%$ has brushed for more than two times a day during first two years of life using $\mathrm{F}$ dentrifices and some using more than pea sized tooth paste during first year of life.

However in our study, this factor was excluded as most of the rural population was deprived of the use $\mathrm{F}$ supplements and $\mathrm{F}$ containing dentrifices. There was no significant difference between the groups(with and without DF) with DMFT \& DMFS scores. This reflects that there is some genetic component which plays a role in etiology of fluorosis Coincidentally there was a significantly higher prevalence of fluorosis among kharra $(36.1 \%)$ \& gutkha $(25 \%)$ chewers as compared to non-chewers $(\mathrm{p}<0.05)$. 
Genetics and fluorosisDF and polymorphism in COL1A2 gene among Chinese children ${ }^{14} 95 \%$ of DF occurs strong heritability components. A/J strain more susceptible than $1-9 \mathrm{P} 3 / \mathrm{J}$ strain to $\mathrm{DF} .^{15}$

The Future prospectus of the study is further analytical studies needs to be conducted.

Fluoridated areas should also be studied for further comparison and complete region should be studied.

\section{Conclusion}

1. The F content \& pH of water was found to be within permissible limits.

2. The prevalence of DF amongst individuals with positive family history $(75 \%)$.

3. There was no correlation with DF and F concentration in drinking water, however its strong correlation exists with genetic component.

\section{Source of funding}

None.

\section{Conflict of interest}

None.

\section{References}

1. Den Besten PK. Dental fluorosis: its use as a biomarker. $A d v$ Dent Res 1994;8(1):105-10

2. Xiang J. Fluoride. 2004;37(1):1-10.

3. Elías-Boneta, W. Psoter, A.E. Elías-Viera, P. Jiménez and C. Toro. Relationship between dental caries experience (DMFS) and dental fluorosis in 12-year-old Puerto Ricans. Comm Dent Health 2006;23:244-50.

4. Williamsl. Community Dent \& Oral Epi.2006;34(1):1-10.
5. Ten cate AR. Oral Histology. 1994; $4^{\text {th }}$ ed.Mosby

6. Russell AL. Dental fluorosis in Grand Rapids during the seventeenth year of fluoridation. J Am Dent Assoc 19391962:65:608-12.

7. Butler WJ, Segreto V, Collins E. Prevalence of dental mottling in school-aged lifetime residents of 16 Texas communities. Am J Public Health 1958;75:1408-1412.

8. Williams JE and Zwemer JD. Community water fluoride levels, preschool dietary patterns, and the occurrence of fluoride enamel opacities. J Pub Hlth Dent 1990;50:276-81.

9. Pendrys DG. Risk of enamel fluorosis in fluoridated and optimally fluoridated populations:considerations for the dental professionals. JADA 2000;131:746-755,

10. Mascarenhas AK. Risk factors for dental fluorosis: A review of the recent literature. Pediatrr Dent 2000;22:269-77

11. Choubisa SL. Endemic Fluorosis In Southern Rajasthan, India. Fluoride 2001;34(1):61-70.

12. Hussain J, Hussain I, Sharma K.C. Fluoride and health hazards: community perceptionin a fluorotic area of central Rajasthan (India):an arid environment. Environ Monit Assess 2010;162:1-14.

13. Gopal R \& Ghosh P.K. Fluoride in Drinking Water. Its Effects and Remova. Def Sci J 1985;35(1);71-88.

14. Hui Huang, Yue Ba, Liuxin Cui, Xuemin Cheng, Jingyuan Zhu, Yuling Zhang, et al.COL1A2 gene polymorphisms (Pvu II and Rsa I), serum calciotropic hormone levels, and dental fluorosis. Comm Dent Oral Epidemol 2008;36( 6):517-22.

15. Everett E.T. Fluoride's Effects on the Formation of Teeth and Bones, and the Influence of Genetics. J Dent Res 2011;90(5):552-60.

How to cite: Makade CS, Shenoi P, Gunwal M, Kubde R, Uttarwar V, Pradhan M, Mokhade V. Prevalence and genetic correlation evaluation of dental fluorosis in rural population of Nagpur, India. Indian J Conserv Endod 2020;5(1):1-3. 